\title{
The Educational Perspectives of Makian People on Nhaguru Philosophy
}

\author{
Bakar Djibat \\ Department of Education Science, Faculty of Education, Universitas Muhammadiyah Maluku Utara, Ternate, Indonesia
}

Received August 8, 2020; Revised October 15, 2020; Accepted October 24, 2020

\section{Cite This Paper in the following Citation Styles}

(a): [1] Bakar Djibat, "The Educational Perspectives of Makian People on Nhaguru Philosophy," Universal Journal of Educational Research, Vol. 8, No. 12, pp. 6491-6497, 2020. DOI: 10.13189/ujer.2020.081214.

(b): Bakar Djibat (2020). The Educational Perspectives of Makian People on Nhaguru Philosophy. Universal Journal of Educational Research, 8(12), 6491-6497. DOI: 10.13189/ujer.2020.081214.

Copyright $\mathrm{C} 2020$ by authors, all rights reserved. Authors agree that this article remains permanently open access under the terms of the Creative Commons Attribution License 4.0 International License

\begin{abstract}
This study aims to analyze and reveal the philosophy of "Nhaguru" from the Makian people's education in North Maluku province. In this study, the qualitative method uses a phenomenological approach by making humans the main research, especially the Makian people in the North Maluku. Only humans can "Nhaguru" or become teachers; that is to say, even non-human beings must be taught by humans, and only humans, if before God, have the highest rank among other creatures. What distinguishes humans from other creatures is that humans are equipped with reason, thoughts, feelings, love, and beliefs to enhance life quality. Humans are self-aware and self-aware subjects. Humans are subjects who are aware of their existence. They can distinguish themselves from everything that is outside themselves. Humans can think about themselves and their surroundings and be mindful of their thoughts. Even though humans are aware of the difference with nature, humans are part of it in the context of the whole of nature. Humans can question the origin of their existence. Education is the process of changing the attitudes and behavior of a person or people group to mature humans. Humans must be humanized because someday they will humanize humans, and this process must be through education. Education is a process of educating, guiding, or helping. Education is an attempt to humanize humans to reach maturity. Because God created humans with a mind and mind, humans need to develop their lives to satisfy their curiosity. This study's results are expected to reveal why every Makian family in North Maluku always has family members who become teachers.
\end{abstract}

Keywords Teacher, Humanize Humans, Educational Perspective, Makian People

\section{Introduction}

The chapter one, article one of Indonesian law number 14/2005 concerning teachers and lecturers, defines a teacher as the professional educator with the main task of educating. It also shows the importance of teaching, guiding, directing, training, assessing, and evaluating students in early childhood through formal, primary, and secondary education. Therefore, it means lesson is a profession requiring devotion to the education field through patterned, legal, and systematic educative interaction. Teachers expected to be trusted and imitated because of their charisma and intelligence. Meanwhile, Fiona King defined a teacher as an individual with the ability to organize and manage the class [1].

Teachers trained to design learning programs and manage classes to ensure students learn and ultimately achieve educational maturity. Djibat also showed they are the central figure and success determinant for students to achieve expected goals [2]. A teacher's existence is closely related to its ability to teach students and a good understanding of the vision, mission, and ability to analyze the work to be conducted on an implementation basis [3]. Moreover, they are required to develop analytical skills to evaluate the strengths, weaknesses, potential opportunities, and threats attached to the students and their profession [4].

According to Faulkner et al., a smart teacher with adequate analytical power is more likely to excel and successful [5]. Teachers play an influential and significant role in their students' success by being models concerning 
dressing discipline, maintaining personal hygiene, always fulfilling worship obligation to God, adequate attendance level in school, appropriate use of time, respectful communication, and showing respect to everyone and family life. However, Kasa showed that few negative stigmas could weaken the teacher's image based on people's opinions and mass media coverage [6]. It is, therefore, means there is generally the need for a fair attitude from both the teacher and community to identify the character required to achieve professionalism and create an educated community. Teachers' social competencies society specific, automatically developed, and depend on social groups. It reflected in their ability to exhibit specific attributes and character, maintain a relationship with each level of social strata in society, and improve their productivity as intellectuals.

Teachers are honorable, dominant, and maintain a high social status such that more than $85 \%$ of Makian parents want their children to "become a teacher." Moreover, improving teachers' professionalism and social competence requires playing more active and productive roles in the community. It means their obligations exceed classroom face-to-face learning activities with students, and they also need to strengthen their position and role in society. It is necessary because their efficiency and effectiveness depend on people's perceptions of their personal qualities and competencies in discharging their duties. However, a teacher's social position varies significantly with region and time. For example, a majority of Makian people believe they are problem solvers. This position requires both the teachers and the community to exhibit fair attitude and character as professionals and society, respectively.

Concerning these definitions and descriptions, is it possible for just anyone to become a teacher? Need consideration of appearance and dedication characterized by expertise in both material and method and the ability to conduct responsibilities required from a professional teacher. According to Helen Timperley et al., professional teachers are expected to be responsible for students, parents, society, nation, and country [7]. It reflected in their role as a determining factor in the success of any educational effort. They are an integral part of every educational innovation, especially in the curriculum and human resources enhancement. The teachers also determine the education quality and personality of students due to the direct contact between them. Therefore, they expected to be competent, responsible, skilled, and highly dedicated. Teachers are simply a walking curriculum.

The existing curriculum and education system requires teachers' input and ability to be successful, and this is associated with their competence and responsibility to oversee students' development. Moreover, the teacher's mentoring process's ultimate goal is to ensure students grow to become fully mature individuals. Therefore, this study conducted to determine the meaning contained in
Nhaguru as a pearl of local education wisdom, especially for the Makian people of North Maluku province.

\section{Literature Review}

\section{Human and Education}

The discussion about humans is constant as long as they continue to live, and a more in-depth exploration shows their extraordinary character. The variations in human uniqueness have led to the creation of several scientific disciplines, including social philosophy, biology, psychology, sociology, anthropology, and several others hidden by the power of human thought. Moreover, according to Keller et al., efforts towards determining human nature require at least their social events, origin, functions, purposes, and potentials in comparison with other creatures [8]. Therefore, discussing teachers means discussing humans because they are the only ones who can become teachers even though other creatures also taught. It is associated with the fact that they are created and equipped with God's reasoning ability, and mind. However, these innate abilities can only be developed through education to satisfy their curiosity about life [9].

The Makian figure in South Halmahera showed several other words that used to replace Nhaguru, and they include Lhaguru, Mhaguru, and Hhaguru. In the Indonesian language, Nhaguru and Lhaguru mean a teacher, while Hhaguru means a father/mother becoming a teacher. The father/mother, in this sense, indicates older people with higher social status. Meanwhile, Mhaguru means "you become a teacher" with several other meanings contained in these words [10]. Humans are interested and have a desire to know everything, and this has led to the impulse of asking questions about themselves and the things external to them. It achieved through several approaches, such as the use of common sense, science, philosophy, religion, and different perspectives from biology, sociology, anthropobiology, psychology, politics, and others [11]. Humans are different in many ways, ranging from physical appearance, social strata, habits, to knowledge about human variety, according to each person's approach and perspective [12]. They are not expected to be the same simply because they are humans [13] but, according to Stierl 2018 some of their similar essential characteristics known as human nature [14]. It exhibited in their uniqueness and individual dignity [15]. For example, they are rational animals symbolized as homo feber, homo sapiens, and homo sicius.

Understanding human nature is complicated, and precisely an anthropological task [16] with the philosophy focused on determining the fundamental characteristics distinguishing humans from other creatures, principally. Some of the related matters include discussing the 1) origin of humans either from evolution or God's creation, 2) 
essential physical structure, body or soul, and 3) several individual and social meanings of existence.

It means the ideas and philosophies centered on distinctive human characteristics [17]. These include their origin as God's creatures or otherwise, metaphysical structure as a unitary body, and reasons for existence as individual, social, enlightened, moral, and spiritual beings.

Education used as a social strategy to maintain the nature of humanity, which means it is impossible to separate humans from the education process [18] because their existence depends on it. Excellent and superior education produces superior individuals and vice versa. According to Patrick, an individual growth and development required a process, education [19]. Thornberg also showed an individual educated as a baby through a mother's love is usually positively influenced [20]. Therefore, education is a process formulated and implemented by humans to maintain the existence of humanity [18].

The education functions as the necessities of human life, social service, guidance, and a mean to shape and improve students' lives and help them achieve their life goals. Educators are required to understand human nature through actualities, possibilities, and idealities and foster desirable changes. It means there is a close relationship between these two concepts: humans without education lose their existence. In contrast, education without humans is useless because only human beings can be educated [21]. Therefore, there is a need to understand all sides of humanity and humanize them while acquiring education.

\section{Local Wisdom}

Nhaguru is the local wisdom of the North Maluku Makian people currently maintained because of its profound philosophy. Meanwhile, local wisdom defined as the knowledge, doctrine, social habits, and practices passed down from one generation to another through socialization. Cabot explains that the concept determines community values and morals by differentiating between right and wrong. Local wisdom is selected based on values and knowledge systems to determine the nature and cognitive style of the people [1] to provide awareness about the previous identity associated with an area. Moreover, most experts, including Robbins, defined the concept as a human effort applied through the intellect to act and behave towards an object or event occurring in a particular space [22].

For the Makian ethnic group, local wisdom is inherent in almost each of their daily activities, including songs, dolabololo, sayings, offerings, advice, motto, and ancient books. Nasuha Adjam, a South Halmahera community leader, interviewed on August 12, 2019, said that local wisdom reflected in the long-standing habits of the Makian people. It integrated into the values of different groups in the community and has become an integral part of their lives, as observed through their daily attitudes and behaviors.

\section{Social Solidarity}

Nhaguru is a fundamental philosophy concerning the lives of Makian people because it contains strong social solidarity, especially in education. Meanwhile, social solidarity defined as the central theme of shaping social order in a society. Moral authority originates from something rather vague called society, and based on two philosophies, including collective consciousness and collective picture. Collective consciousness varies from one community to another. A composite image is symbols representing the same meaning for all members of the city, which allows them to feel the same and share a similar fate. For this study, collective awareness involves training everyone in the Makian family as a teacher. It contained in Nhaguru philosophy, and each family observed to be using it to achieve their interests.

\section{Research Method}

A qualitative method with a phenomenon approach used to determine the educational perspective of Nhaguru philosophy among the Makian people towards ensuring a member of the family becomes a teacher. It also intended to maintain local wisdom and build social solidarity for North Maluku people by describing several variables related to the problem.

The study conducted for twelve months from January to December 2019 in three districts/cities in North Maluku Province. Including South Halmahera regency, Ternate city, and Tidore Kepulauan city selected because they consist of Makian people that preserve and uphold local culture and wisdom, especially Nhaguru.

The research areas were determined based on research objectives and methods, as well as the required data. The first was South Halmahera Regency selected based on suggestions and recommendations from the district's education and culture branch office head due to its recognition as the origin of Nhaguru. The second was Tidore Islands City selected due to the fact the culture and values of local wisdom upheld despite the settlement of multi-ethnic groups in North Maluku. Meanwhile, the third was Ternate City, recognized as the icon of North Maluku Province, whose population is also multi-ethnic and dominated by Ternate, Makian, and Tidore.

The data collected through observation, in-depth interviews, and documentation. Primary data obtained from traditional elders and community leaders from the three districts/cities, while secondary ones include the signs of Nhaguru philosophy implemented.

The data were analyzed using the Creswell model [23] considered the most complete and up-to-date technique. It involved using six steps to illustrate linear and hierarchical 
relationships built from the bottom-up while an interactive approach was applied to determine the interrelationships between the stages.

\section{Results and Discussion}

\section{Nhaguru from the Educational Perspectives of the Makian People}

The results showed there is a strong relationship between education and culture, which means it is impossible to sustain culture without the education process. Nhaguru implicitly means the educational process also involves cultural transmission. Meanwhile, from the Anthropology perspective, education is transforming the socio-cultural system from one generation to the next in society. Tawary (a Ternate community figure from Makian/interview dated July 24, 2019), explained that the philosophy contained in Nhaguru is a cultural education process and this is the reason culture exists in every discussion about education. It also means the praxis of education is always within the scope of learning, and the only intelligent creatures of God are humans. According to Tawary (interview, July 25, 2019), humans in Nhaguru philosophy are those able to be educated and with the capability to teach others. When Makian parents asked what they want their children to become, most is always "teacher" or, in Makian language, Nhaguru.

Human beings found to be substantially different from other creatures. It reflected in the cultural privilege of being educated, the ability to accept God's mandate as leaders on earth, and equipped with several skills and facilities, both physical and spiritual. Furthermore, Madjid (interview November 27, 2019) mentioned humans are described in the Holy Qur'an, first, with letters alif, nun, and sins such as insan, second, the word basyar, and third, bani Adam or zurriyat Adam which are related to human understanding. However, from the holy book's explanation, these three words have different meanings; for example, Al-basyar means humans' material image based on the ability to eat, walk, and make efforts towards fulfilling life. It shows humans are biological creatures. Meanwhile, the word Al-nas refers to humans as social beings and used in many verses of the Holy Quran to represent a group of people.

The majority of the Makian people in the three districts/cities argued Nhaguru philosophy was the key to parents' success in educating their children to become teachers. According to Salama (interview, August 11, 2019), Makian people believe a teacher can teach others, especially the family, and Nhaguru is a pearl of local wisdom that needs to be maintained. Meanwhile, one of the major problems is how to implement this local wisdom to build character education in society. In response to this challenge, Jainal Ali (interview, August 19, 2019) believed there is a need to revitalize local culture (local wisdom) to build character education. It expected to make every child love their region, which further creates regional resilience, which has defined as citizen's ability to organize themselves based on real philosophy with a healthy soul, high spirits, and wise use of nature.

All children in three districts/cities were observed not to have an understanding of Nhaguru. Therefore, they naturally need to be introduced to their closest environment, village, sub-district, and district before national and international levels to create the love of their immediate environment or community. It further expected to make them work in and for the village. Local wisdom, such as Nhaguru has a significant meaning for students due to its ability to make them understand the struggle of their ancestors in different social activities. This research also found that Nhaguru philosophy contains the values of hard work, persistence, resilience, enthusiasm, courage, and taking risks required to teach children. Therefore, Nhaguru is very suitable for character education and should be introduce to every child.

According to Kasim Sudin, one of the Ternate city community leaders (interview, September 5, 2019), humans are not automatically human after birth. Because, the first step to knowing the world and, even though they are not fully aware, they recognize their existence at that instance. It means they are just an entity consisting of bones wrapped in flesh and skin with all the features possessed. At this stage, humans generally recognized and accepted by others to face the world and all its dynamics.

Makian people believe the education process needs to start from the pregnancy period by receiving and serving guests sincerely and adequately, greeting people according to age and social level, and differentiating people with higher knowledge from those with lesser. Meanwhile, Husen H. Umar (South Halmahera community figure, interview October 18, 2019) stated that "humans can determine how long they will live because if they always do good. They expected to live longer and be a blessing by humanizing and teaching others, and this guarantees them a place in Heaven." The statement not entirely justified, the existence of other assumptions such as the initiation of education in the womb, which also considered. Apart from the time difference, both assumptions indicate education is an integral part of humans throughout the ages. In the most basic sense, a culture defined as the process of humans humanizing others.

The idea of humanizing human beings, which means the same as Nhaguru for Makian people, was also discovered. According to the very famous slogan "Sitow Timow Tumow Tow" from Samratulangi, which means not reducing it into the paradigm of objectivity, rigidity, and closeness. From a perspective, humans are observed as a form of matter like other creatures, while, in another, they are people with personalities and individual identities not possessed by other beings. They are civilized and build relationships with others, but this requires education to reach its culmination. Moreover, education also found to be 
a process of double change, first, the changes in human beings due to existence, and, second, integrating with the changes in society and culture.

The results also showed that apart from the advantages associated with changing times. There are some negative impacts always ignored and which cannot be explicitly absorbed. According to Sukri Abdullah, a Ternate community leader from Makian (interviewed November 11, 2019), only a few people can identify and realize it. Moreover, according to Makian people, the teacher is an individual with the ability to explain the slightest thing about something, a child, or an adult with the attributes of a role model (Yusuf, South Halmahera community leader, interview December 2, 2019). Their families are used as a reference and expected to have advantages not possessed by others and the ability to control natural phenomena. Based on these criteria, Husen Sangadji (South Halmahera figure/interview December 10, 2019) believed Nhaguru philosophy involves someone working by explaining science to others starting from the immediate family environment without expecting anything such as wages, salaries, and gifts in return. It means the focus is on ensuring humans can educate, learn, teach, and manage.

Moreover, the education process is not only in school but also in the community, environment even for plants and animals. It shows the teacher is a blessing to all creatures by playing a crucial role in different social activities. It also serves as an essential element with a tremendous responsibility in the general education of society.

The Makian people expect teachers to show superiority because of the demands and responsibilities and the advantages they have over others. A teacher needs time to realize the professional function. At the same time, the community also expected to support the efforts made towards organizing education and making changes by conveying knowledge, developing potentials, and shaping students' character to help them conquer and achieve their goals. Therefore, the teacher is a person with the ability to create the future.

\section{The Value of Solidarity in the Philosophy of Nhaguru}

According to this study, this value understood to be an abstract thing serving as a guide and general principle for human actions and individual goals. The social attachment to value observed to be relatively robust and emotional, as followed by the Nhaguru, which is a cultural value ensuring people live meaningfully. Its philosophy contains a social system manifesting the thoughts considered essential and valuable to people's lives.

The existing value system of this culture is used as a reference for different behaviors and determines alternatives, ways, tools, and educational goals. Syafi Tawary, a South Halmahera community leader (interviewed on October 28, 2019), explained Nhaguru value as an organized philosophy that influences behaviors related to nature, position, relations, and desirable and undesirable things related to humans, environment, and others. It merely involves educating humans to have high solidarity.

This study also found that the North Maluku people can regulate their actions and behaviors, especially concerning sending their children to school, through Nhaguru philosophy. It is an institution considered necessary by the community due to its ability to regulate every citizen's role in providing education. It also improves individual and family relationships using the integrated value system by ensuring every citizen complies with the applicable value system to avoid being shunned by the community and other families.

The results showed the Nhaguru philosophy is continuously maintained and developed by the people, especially the Makian ethnic group, up to the present time due to its environmental and socio-cultural usefulness. As a socio-cultural system, Nhaguru saw as a solution to the problem of sending children to school and regulating and forcing citizens, including members of the community and new residents, to act by applicable values. The values contained in the culture are high and are respected because they exist before humans and also expected to be functional after them.

Nhaguru philosophy also found to be able to regulate human social behavior and practical and economic value based on the voluntary contribution, in terms of energy, thought, time, goods, and money, from community members to help families sending their children to school. Moreover, the culture also creates closer moral ties between families and individuals in society by connecting stretched brotherhood ties and easing conflicts.

Solidarity values are evident in the Nhaguru culture because people observed to be feeling the same fate and required to collaborate to ensure the completion of their children's education. Moreover, there is no difference between social class and age as well as old and new residents, and this further depicts the egalitarian spirit and solidarity. Naturally, almost all Makian families have at least one teacher and, there are some, where everyone is a teacher. The people's social solidarity shown by their willingness to sincerely sacrifice materials, energy, and time and other things with no strings attached.

\section{Conclusions}

Nhaguru is a culture that has been existing, growing, and developing for a long time in society, especially among the Makian ethnic group of North Maluku province. It is culture loaded with educational values such as sending children to school and represented by four words with almost the same meaning and object, humans, but different philosophies, Nhaguru, Mhaguru, Lhaguru, and Hhaguru. It discovered that Nhaguru, Mhaguru, and Lhaguru, means 
"he/they became a teacher," while Hhaguru means "father/mother became a teacher." These words observed to have emphasized humans should become a teacher to themselves, their families, society in general, and even to other creatures. Their responsibility is not limited to the students in school but to humanize humans and become role models in the family, community, environment, animals, and others. They also expected to have the ability to control natural phenomena and be perfect human beings.

Nhaguru culture, as local wisdom, contains educational values and social solidarity required to be maintained and developed, such as the spirit of cooperation, egalitarianism, feeling the same fate, and the vision of sacrificing time, material, and energy for others. Therefore, it creates a sense of togetherness and high social solidarity by reducing the burden on families to send their children to school and several tensions in the community and erode individualistic attitudes. The philosophy contained in the culture includes education values and social sanctions, which make people have strong moral ties, and this means everything does not always judged materially. The culture strengthens the sense of togetherness and creates harmony and cooperation in the community.

\section{Acknowledgments}

The high appreciation for all Makian informants and all who have to contribute and discussed during this research. Our great thank to all reviewers that corrections and suggestions.

\section{REFERENCES}

[1] King, Fiona. 2019. "The Impact of Policy on Leadership Practice in the Irish Educational Context; Implications for Research." Teachers' Journal 7 (1): 57-73.

[2] Djibat, Bakar. 2017. "The Development Of Quality Schools Based On Local Wisdom In Ternate North Maluku." International Journal of Scientific \& Technology Research 6 (5): $82-86$

[3] Bhimji, Fazila. 2016. "Collaborations and Performative Agency in Refugee Theater in Germany." Journal of Immigrant and Refugee Studies 14 (1): 83-103. https://doi.org/10.1080/15562948.2015.1024813.

[4] Gillespie, Marie, Souad Osseiran, and Margie Cheesman. 2018. "Syrian Refugees and the Digital Passage to Europe: Smartphone Infrastructures and Affordances." Social Media and Society 4 (1). https://doi.org/10.1177/20563051187644 40.

[5] Faulkner, S, Farida Vis, and Francesco D'Orazio. 2018. "Analysing Social Media Images." In The SAGE Handbook of Social Media. Los Angeles, California: Sage.

[6] Kasa, Başak, and Yasemin Ersöz. 2016. "Pros and Cons:
Compulsory 12 Year Education Reform in Turkey." South African Journal of Education 36 (2): 1-10. https://doi.org/10.15700/saje.v36n2a1197.

[7] Timperley, Helen, Aaron Wilson, Heather Barrar, and Fung Irene. 2007. Teacher Professional Learning and Development: Best Evidence Synthesis Iteration [BES]. Wellington, New Zealand: The Ministry of Education New Zealand.

[8] Keller, Jessalynn, Kaitlynn Mendes, and Jessica Ringrose. 2018. 'Speaking 'Unspeakable Things': Documenting Digital Feminist Responses to Rape Culture." Journal of Gender Studies 27 (1): 22-36. https://doi.org/10.1080/0958 9236.2016 .1211511$.

[9] Milan, Chiara. 2018. "Emotions That Mobilise: The Emotional Basis of Pro-Asylum Seeker Activism in Austria." Solidarity Mobilizations in the 'Refugee Crisis,' 183-208. https://doi.org/10.1007/978-3-319-71752-4_7.

[10] Abdjan, Yakub. 2019. "Interviews."

[11] Chouliaraki, Lilie, and Rafal Zaborowski. 2017. "Voice and Community in the 2015 Refugee Crisis: A Content Analysis of News Coverage in Eight European Countries." International Communication Gazette 79 (6-7): 613-35. https://doi.org/10.1177/1748048517727173.

[12] Kallius, Annastiina, Daniel Monterescu, and Prem Kumar Rajaram. 2016. "Immobilizing Mobility: Border Ethnography, Illiberal Democracy, and the Politics of the 'Refugee Crisis' in Hungary." American Ethnologist 43 (1): 25-37. https://doi.org/10.1111/amet.12260.

[13] Bigo, Didier. 2014. "The (in)Securitization Practices of the Three Universes of EU Border Control: Military/Navy Border Guards/Police - Database Analysts." Security Dialogue 45 (3): 209-25. https://doi.org/10.1177/09670106 14530459 .

[14] Stierl, Maurice. 2018. "A Fleet of Mediterranean Border Humanitarians.” Antipode 50 (3): 704-24.https://doi.org/10 .1111/anti.12320.

[15] Bleiker, Roland, David Campbell, Emma Hutchison, and Xzarina Nicholson. 2013. "The Visual Dehumanisation of Refugees." Australian Journal of Political Science 48 (4): 398-416. https://doi.org/10.1080/10361146.2013.840769.

[16] Sajir, Zakaria, and Miriyam Aouragh. 2019. "Solidarity, Social Media, and the 'Refugee Crisis': Engagement beyond Affect." International Journal of Communication 13: 550 77.

[17] Boudreau Morris, Katie. 2017. "Decolonizing Solidarity: Cultivating Relationships of Discomfort." Settler Colonial Studies 7 (4): 456-73.https://doi.org/10.1080/2201473X.20 16.1241210 .

[18] Şahin, Ümran. 2019. "Values and Values Education As Perceived By Primary School Teacher Candidates." International Journal of Progressive Education 15 (3): 74 90. https://doi.org/10.29329/ijpe.2019.193.6.

[19] Patrick, John. 2004. "The Civic Mission of Schools: Key Ideas in a Research-Based Report on Civic Education in the US." Teacher Librarian 32 (2): 26.

[20] Thornberg, Robert. 2008. "The Lack of Professional Knowledge in Values Education." Teaching and Teacher 
Education 24 (7): 1791-98. https://doi.org/10.1016/j.tate.20 08.04.004.

[21] Schwartz, Shalom H., Gila Melech, Arielle Lehmann, Steven Burgess, Mari Harris, and Vicki Owens. 2001. "Extending the Cross-Cultural Validity of the Theory of Basic Human Values with a Different Method of Measurement." Journal of Cross-Cultural Psychology 32 (5): 519-42. https://doi.org/10.1177/0022022101032005001.

[22] Schwartz, Shalom H., Gila Melech, Arielle Lehmann,
Steven Burgess, Mari Harris, and Vicki Owens. 2001. "Extending the Cross-Cultural Validity of the Theory of Basic Human Values with a Different Method of Measurement." Journal of Cross-Cultural Psychology 32 (5): 519-42. https://doi.org/10.1177/0022022101032005001.

[23] Creswell, John W., William E. Hanson, Vicki L. Clark Plano, and Alejandro Morales. 2007. "Qualitative Research Designs: Selection and Implementation." The Counseling Psychologist 35 (2): 236-64. https://doi.org/10.1177/00110 00006287390 . 